\title{
ICT-Based Improvement of Construction Procurement Process
}

\author{
Olli Martikainen ${ }^{1,2}$, Raija Halonen ${ }^{1,3}$, and Valeriy Naumov ${ }^{1}$ \\ ${ }^{1}$ University of Oulu, Department of Information Processing Science, Oulu, Finland \\ ${ }^{2}$ The Research Institute of the Finnish Economy, Helsinki, Finland \\ ${ }^{3}$ National University of Ireland, Centre for Innovation \& Structural Change, Galway, Ireland \\ \{olli.martikainen, raija.halonen, valeriy.naumov\} @oulu.fi
}

\begin{abstract}
The research by Maliranta and Rouvinen based on the Finnish industrial statistics confirms that the productivity improvements in ICT services in firms correlate to organizational and process changes. These results implied a further question: Which types of process changes create the most beneficial productivity improvements in different environments? In this paper we apply the Three Viewpoint Method (3VPM) approach, originally developed for the productivity analysis of process changes, to analyze the improvement of the construction procurement process of a large Scandinavian construction company when an IT system for procurement was taken into use in the Finnish offices. The analysis revealed that implementing the procurement IT system decreased worker utilization rates and improved the procurement process throughput.
\end{abstract}

Keywords: Business process analysis, procurement process, IT-system, process improvement, Three Viewpoint Method.

\section{Introduction}

The productivity increase results from ICT (Information and Communication Technologies) in the industry and in the society are of rather recent origin [1, 2]. Furthermore, the benefits derived from ICT have been experienced arduous to calculate [3]. The history of ICT implementations is still lacking a positive signal as a mark of successful accomplishment in business improvements $[4,5]$.

According to the prior research it seems that the excess productivity effect of ICTequipped labor typically ranges from eight to eighteen per cent. The effect tends to be larger in services than in manufacturing. The effect is often manifold in younger and can even be negative in older firms. Since organizational changes are easier to implement in younger firms and recently established firms have by definition a new structure, this can be interpreted as evidence for the need for complementary organizational changes. Manufacturing firms seem to benefit from ICT-induced efficiency in internal whereas service firms benefit from efficiency in external communication. These results, however, fail to explain, what really happens in the organization, when large productivity improvements are observed. 
The literature has contributed to IT benefit measurement and management in four major areas: Performance improvements, the issue of information systems reach tangible and intangible benefits and benefit evolution [6]. The benefits from process changes when workflow systems have been introduced are measured in [7]. In their extensive literature review Melville et al. [8] introduced a model of a resource-based view of a firm (RBV) that builds on intellectual foundations (theory of imperfect competition, theory of monopolistic competition, theory of firm growth) and theory development (resource-based view of the firm, resource heterogeneity and above normal firm performance, identification of resources that confer a sustained competitive advantage, bundling of resources). Melville et al. [8] confirm that IT is valuable and offers potential benefits ranging from flexibility and quality improvements to cost reduction and productivity enhancement. They also propose that the high degree of complexity leads to a context-contingent set of synergistic combinations of IT and other organizational resources such as workplace practices, change initiatives, organizational structure and financial condition. Therefore they suggest further case and field studies of specific organizational contexts. Our work continues this research by presenting a formal process modeling and analysis framework, the Three Viewpoint Method (3VPM), for the calculation of the benefits created by the process changes enabled by the new ICT services. The approach is appropriate in any business process analysis that fulfills the required steps [9].

Prior literature has only little knowledge so far of what the best practices in organizing ICT-assisted work will be. Nevertheless, it is obvious that in the future when the ICT benefits are optimally applied in new process forms, the job descriptions will ultimately differ considerably from the current ones. Likewise, prior research sets forth experiences from computational approaches to business process design and positive sign concerning the possibility of analytical support for business process design is visible $[10,11]$. The productivity improvements created by ICT services are a result of customer process changes enabled by the IT service. Depending on customer process types different improvements are possible. The benefits from customer process changes should be larger than the cost of the IT service in order the IT service to be feasible.

\section{Business Process Modeling}

Business process was defined by Davenport [12] as a specific ordering of work activities across time and place, with a beginning and end, and with clearly defined inputs and outputs. First approaches of business process development were published in the early 1990's $[13,14,15]$. The term business process re-engineering (BPR) was also introduced at that time [15]. The management and improvement of business processes has after that generated a large amount of literature, including topics Re-engineering the Corporation [16], Process Innovation [12], Improving Performance [17], Business Process Management [18] and Business Process Change [19]. All approaches have the same notion of improving the performance of the organization by developing the business processes.

The first task in business process development is the process modeling, where the necessary features of the process are documented. There are several modeling approaches for this purpose based on Business Process Diagrams such as Business Process Modelling Notation (BPMN) by Object Management Group (OMG) [20], 
Ericsson Penker extension of Unified Modelling Language (UML) [21] and Workflow Nets [22, 23]. Here we apply the UML Activity Diagram notation [21].

When a service is provided for customer's business process or personal process the interaction with the service process changes the customer process in a way that creates the productivity improvements. Usually the utility of the productivity improvements should be larger than the cost of the service. However, in public services the utility is not only the performance improvement in the customer's process but also the utilities created through externalities in the society (Fig. 1).

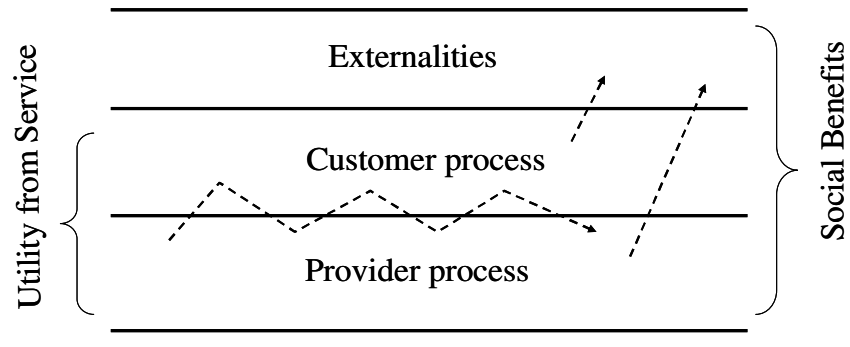

Fig. 1. The benefits created by a service process

In addition to the process diagrams, both performance and cost modeling of the process are needed when productivity improvements are analyzed. We call the modeling approach that uses these three viewpoints: 1) diagrams, 2) performance and 3) cost, as Three Viewpoint Modelling (3VPM). For performance we use queuing network models to calculate the throughput and waiting times of events or tasks in the process and the utilizations of the resources related to the activities of the process [24]. In cost analysis the fixed costs in the process are related to the costs per time unit of the fixed resources involved as well as to the fixed quality costs and fixed risk costs. The variable costs of the process are related to the product of the utilization and the cost per time unit of the variable resources involved as well as to the waiting costs, quality costs and risk costs that depend on the load of the system.

\section{Business Process Analysis}

The micro level analysis of a system of processes is based on the following four steps: Drawing the logical process diagrams of the original and transformed processes, calculating the process performance analysis of the obtained models, calculating the activity based costs of the models and comparing the results of original and transformed models.

\subsection{Create the Logical Process Diagrams}

The first task, with the employees, is to create a cognitive description (a swim line model) of the work process. There are several descriptive models and corresponding graphical editors that can be used. In our analysis we apply the activity diagram notation based on the OMG Unified Modelling Language (UML) with Eriksson Penker business process extensions (see $[20,25]$ ). Both the service processes and the 
corresponding customer processes and their proposed changes should be modeled. The process diagrams specify the logical process model denoted by $\mathrm{M}$.

\subsection{Analyze the Process Performance}

For performance analysis we use the queuing network solution $\mathrm{G}$ for the model $\mathrm{M}$ to calculate the throughput and waiting times of events or tasks in the process and the utilizations of the resources related to the activities of the processes [24]. When the processes are analyzed using the queuing network model, the modeling results can be calibrated with the real system. The calibration often reveals problems or unknown features in the system, and discussion with the process personnel is needed to solve possible inconsistencies. Only after successful calibration the possible process changes can be modeled and their effects analyzed.

\subsection{Calculate the Activity Based Costs}

In the cost analysis the fixed costs in the processes are related to the costs of the fixed resources as well as to the fixed quality costs and fixed risk costs. The variable costs of the processes are related to the product of the utilization and the cost per time unit of the variable resources involved as well as to the waiting costs, quality costs and risk costs that depend on the load of the system. The cost function F divided by the number of service transactions and calculated as a function of load represents the average variable cost curve generated by the production function of the system.

\subsection{Combine the Three Models}

In the Three Viewpoint Model (3VPM) approach the three viewpoints: 1) diagrams, 2) performance and 3) cost are related to each other with common variables (Fig. 2).

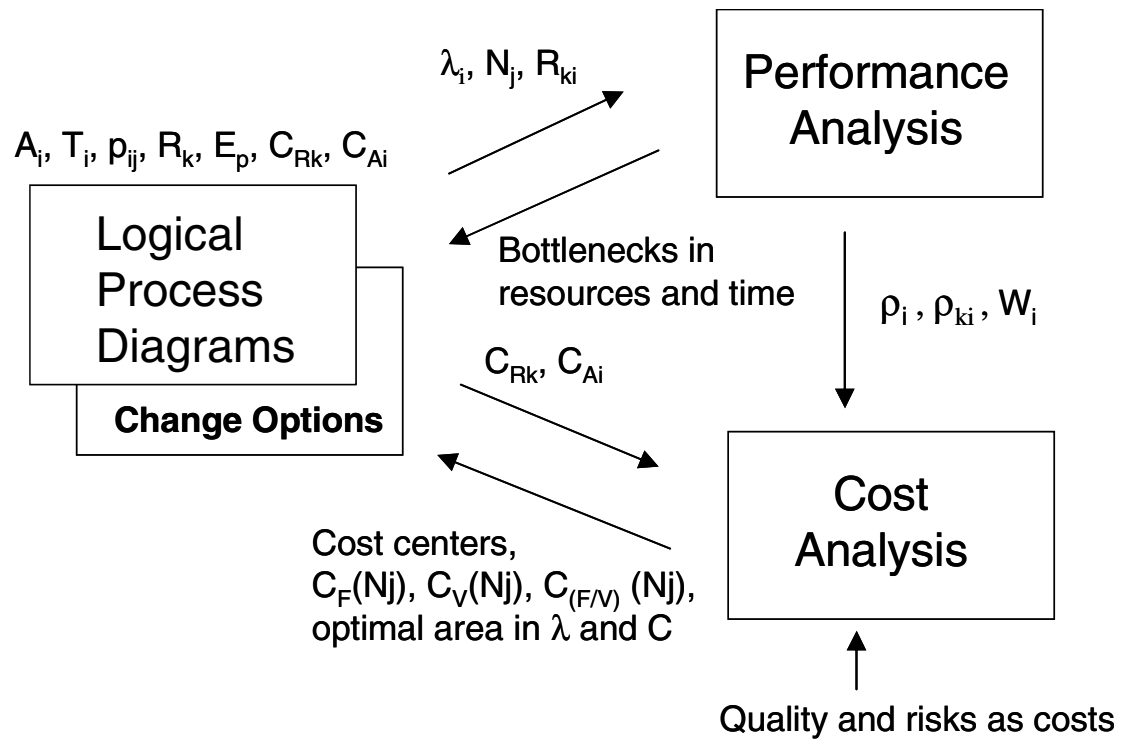

Fig. 2. The 3VPM approach 
In the process diagram the activities $\left(A_{i}\right)$, related resources $\left(R_{k}\right)$, tasks or customers (E) served and the corresponding task arrival intensities $\left(\lambda_{\mathrm{i}}\right)$, routing probabilities $\left(\rho_{i j}\right)$, service times in activities $\left(T_{i}\right)$, population sizes $\left(N_{i}\right)$ and costs of resources $\left(C_{R k}\right)$ are given for the model M. The results are calculated in the 3VPM analysis using the queuing network solution denoted by $\mathrm{G}$ and the cost analysis solution denoted by $\mathrm{F}$. The variables used as input and results obtained as output are displayed in Table 1 and they are related as shown in formulas 1,2 and 3 .

Table 1. Input and output parameters in the 3VPM analysis

\begin{tabular}{lclc}
\hline Inputs & \multicolumn{3}{l}{ Outputs } \\
\hline Activities & $\mathrm{A}_{\mathrm{i}}$ & Customer time in activity $\ldots$ & $\mathrm{W}_{\mathrm{i}}$ \\
Task classes & $\mathrm{E}_{\mathrm{p}}$ & Customers p in activity i & $\mathrm{N}_{\mathrm{pi}}$ \\
Routing probability & $\rho_{\mathrm{ij}}$ & Utilization of activity & $\rho_{\mathrm{i}}$ \\
Service time in activity & $\mathrm{T}_{\mathrm{i}}$ & Utilization of resource k in activity i & $\rho_{\mathrm{ki}}$ \\
Arrival intensity & $\lambda_{\mathrm{i}}$ & Fixed costs & $\mathrm{C}_{\mathrm{F}}$ \\
Customers p in system & $\mathrm{N}_{\mathrm{p}}$ & Variable costs & $\mathrm{C}_{\mathrm{V}}$ \\
Resource & $\mathrm{R}_{\mathrm{k}}$ & & \\
Resource time in activity & $\mathrm{R}_{\mathrm{ki}}$, & & \\
Resource k cost in time & $\mathrm{C}_{\mathrm{Rk}}$ & & \\
Activity I other costs & $\mathrm{C}_{\mathrm{Aj}}$ & & \\
\hline
\end{tabular}

$$
\begin{gathered}
M=\left(A_{i}, T_{i}, r_{i j}, E_{p}, C_{R k}, C_{a j}\right) \\
\left(\rho_{i}, \rho_{k i}, W_{i}\right)=G\left(\lambda_{i j}, N_{i}, R_{k i}, M\right) \\
\left(C_{F}, C_{V}\right)=F\left(\rho_{i}, \rho_{k i}, W_{i}, M\right)
\end{gathered}
$$

The model $\mathrm{M}$ includes the process components and the graphical description. The function $G$ is the solution of the open or closed queuing network representing the process. Usually $\mathrm{G}$ is an algorithm that cannot be given in a closed form. The function F simply calculates the costs based on the resource utilizations and customer delays that are obtained from $\mathrm{G}$.

\section{Construction Procurement Process}

In what follows we analyze the construction procurement process of a large Scandinavian construction company before and after an IT system for procurement was taken into use. The study focuses in the Finnish offices of the company. In order to analyze the original procurement process, the process was described with the help of a graph (Fig. 3). Several key persons from the company were interviewed to find out information about the procurement process at the time. The actual procurement process started with searching the suppliers after the project needs had been specified. As can be seen in Figure 3, the process was partly iterative. The procurement process under inspection is located at the lower half of the chart. 


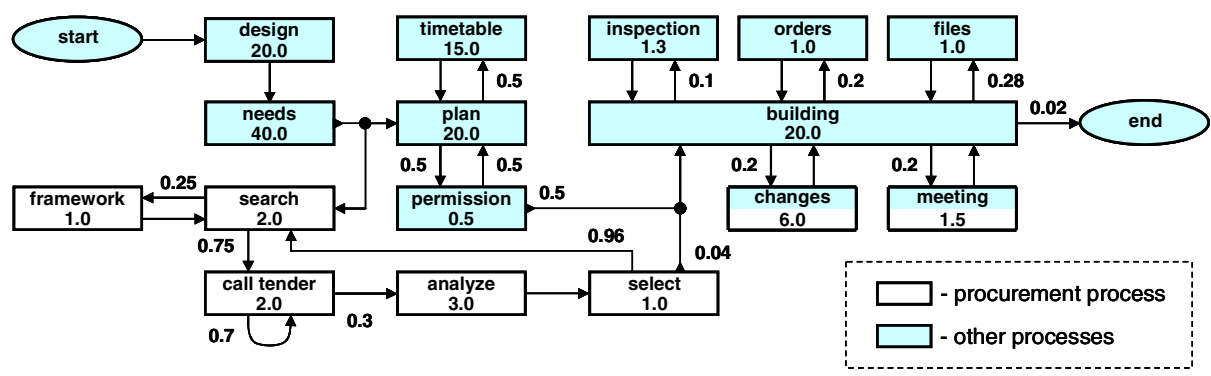

Fig. 3. Procurement Process

As shown in Figure 3, the sample process was loaded with changes that required a lot of resources $(6 \mathrm{hrs})$ parallel to the actual building phase despite the design phase (20 hrs) and requirement analysis ("needs" $40 \mathrm{hrs)} \mathrm{that} \mathrm{lead} \mathrm{to} \mathrm{the} \mathrm{plan} \mathrm{phase} \mathrm{(20} \mathrm{hrs).}$

In the case company, cross-trained employees were qualified and authorized to perform more than one task type. The company had identified six employee categories: 1) architects, 2) engineers, 3) project managers, 4) site managers, 5) area managers, and 6) procurement managers.

The employees were classified according to their skill patterns, which were described by a skill matrix (Table 2). Besides employee categories, the skill matrix included the tasks that were described to be included in the construction procurement process (see Fig. 3). The skill matrix revealed that in the company there were both tasks managed by several professionals and professionals who managed several skills. The skill matrix also revealed the total quantity of each group of professionals per profession and per task type. Furthermore, the skill matrix enabled the estimation of potential changes in the process when the employee-related parameters were changed in the analysis framework 3VPM.

Table 2. Skill matrix

\begin{tabular}{|c|c|c|c|c|c|c|c|c|c|c|c|c|c|c|c|c|}
\hline & 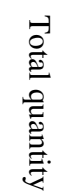 & 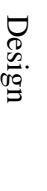 & 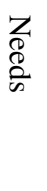 & 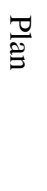 & 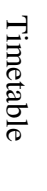 & 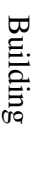 & 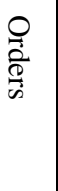 & 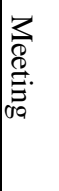 & 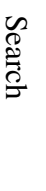 & 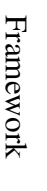 & & 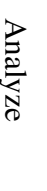 & $\begin{array}{l}\stackrel{\mathscr{Q}}{\otimes} \\
\stackrel{\overbrace{}}{\varrho}\end{array}$ & 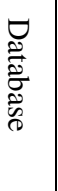 & 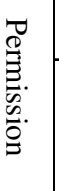 & 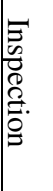 \\
\hline Architect & 10 & $\mathrm{X}$ & $X$ & & & & & & & & & & & & & \\
\hline Engineer & 15 & & $\mathrm{X}$ & $\mathrm{X}$ & & & & & & & & & & & & \\
\hline $\begin{array}{l}\text { Project } \\
\text { manager }\end{array}$ & 15 & & $\mathrm{X}$ & $\mathrm{X}$ & $\mathrm{X}$ & & & & & & & & & & & \\
\hline Site manager & 100 & & & & & $\mathrm{X}$ & $\mathrm{X}$ & $\mathrm{X}$ & & & & & & $\mathrm{X}$ & $X$ & $\mathrm{X}$ \\
\hline Area manager & 6 & & & & & $\bar{X}$ & $\mathrm{X}$ & $\bar{X}$ & & & & & & & & \\
\hline $\begin{array}{l}\text { Procurement } \\
\text { manager }\end{array}$ & 25 & & & & & & & $\mathrm{X}$ & $\mathrm{X}$ & $\mathrm{X}$ & $\mathrm{X}$ & $\mathrm{X}$ & $\mathrm{X}$ & & & \\
\hline
\end{tabular}




\section{Process Transformations}

Next, we present the new process, based on the elaborated skill matrix, cost analysis and original process description influenced by the new procurement IT system Pursys that was recently implemented to manage the procurement process. As the implementation still was in process, Pursys was not in use in every task in the process. The process graph of the sample project (Fig. 4) reveals that the modified procurement process (located at the lower half of the graph) produces significant improvements in two distinct tasks, namely "search" and "changes".

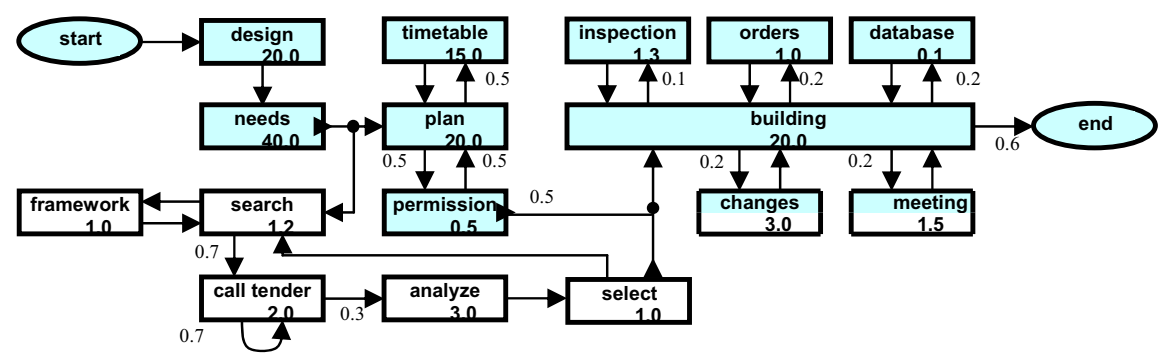

Fig. 4. Improved Procurement Process

The influence of Pursys was theoretically analyzed in relation to the procurement process. While the 3VPM made it possible to estimate and evaluate the process outcomes, the response time was evaluated in three hypothesized cases (Fig. 5).

\section{Response time}

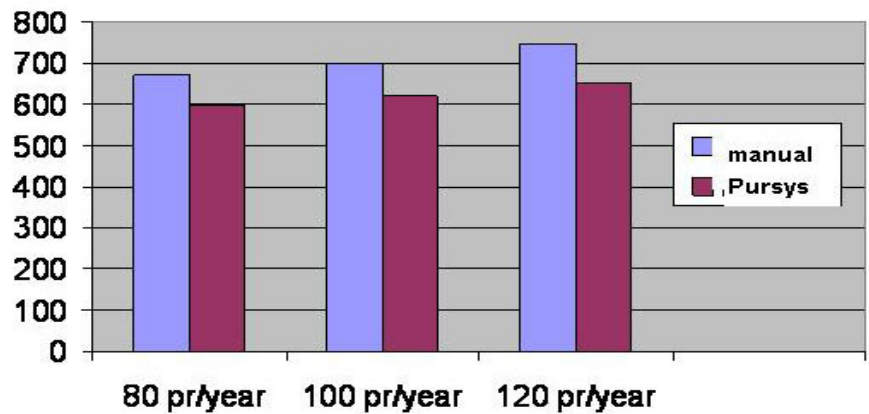

Fig. 5. Improvements in response time (no construction time, arrival rate $=1.6$ )

As described in Figure 5, the improvement of the procurement response time, when one replaces the manual procurement process with the Pursys managed one seems to be almost independent on the number of annual construction projects.

The use of Pursys was further compared with manual process management as the employee utilization (Fig. 6) was evaluated with the 3VPM. 


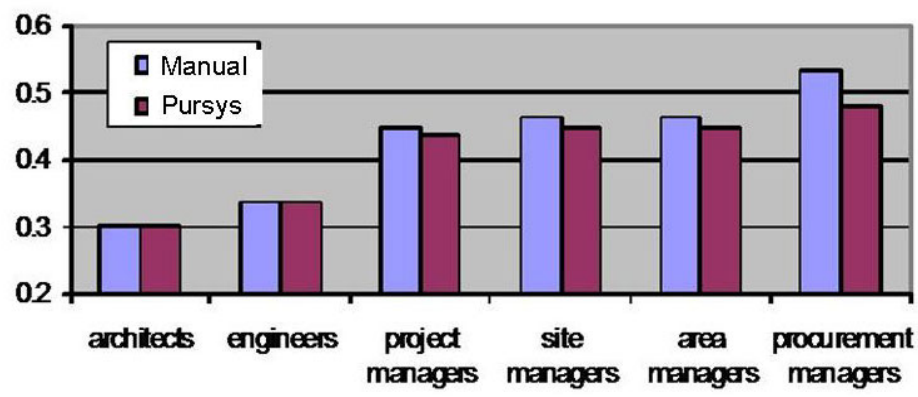

Fig. 6. Improvements in employee utilization (no construction time, arrival rate $=1.6$ )

The use of Pursys did not improve the workload of architects or engineers compared to the legacy system as described in Figure 6. However, even project managers benefited from Pursys even if the change is only modest. The workload of procurement managers was decreased more visibly. The same tendency was seen in the process chart as tasks managed by architects and engineers were not affected by implementing Pursys. On the other hand, procurement managers were in charge when searching suppliers that definitely was improved when Pursys was implemented (see Fig. 4).

All in all, the calculated savings based on the changes in employee utilizations made it possible to assess the Pursys system payback time and to justify the Pursys system investment.

\section{Conclusions}

Prior research has revealed that it is complicated and challenging to investigate the role of ICT when seeking for improvements in productivity in the industry sector $[1,8]$. The problem is not rare in several other sectors [4]. Also, research on productivity increase resulting from ICT in the industry and in the society is of rather recent origin even if it shows that the productivity improvements in ICT services in firms correlate to organizational and process changes [1, 2]. While Melville et al. [8] propose that ICT infrastructure is a complementary asset that shapes the extent to which firms can apply ICT to improve organizational performance; our study highlights the need to evaluate the business processes from three different angles simultaneously.

In our approach we were able to evaluate the existing processes that covered three distinct viewpoints that were related to each other with specified parameters (see Fig. 2). Not only did the model notice the business process that was defined by key professionals in the company but it also paid attention to the costs and performance that were varied according to the presupposed circumstances in the company.

Since there were several improvements but also some drawbacks in the Pursys supported procurement process, compared to the manual one, it was not possible at the beginning to make an expert opinion on the productivity improvement enabled by the Pursys system. After the system was modeled and analyzed with the 3VPM method, the overall productivity improvement and the resource utilizations could be calculated. Also different improvement options could be compared. The drawbacks 
of the 3VPM method were the need of interviews and modeling work. Methods and tools which could at least partially automate the data collection are under study.

In practice, the study showed that in a large enterprise it is important to recognize the several viewpoints that influence the business process. Even small changes in the separate input parameters may lead to great changes in the output. Therefore our study suggests additional research to find out the dependent factors that one by one influence business processes. After that, to further combine those to be used when suggesting future improvements in business processes.

A near future improvement of the 3VPM method will be the automated process data measurement by the aid of a wireless data logging system. A long time goal for the research could be the classification of the best process improvement practices depending on the process type and the ICT application.

Acknowledgments. The authors kindly acknowledge the support from the Protura project from ETLA. The project has been financed by the Finnish Funding Agency for Technology and Innovation (Tekes) and several firms. In addition, SESC and VESC projects financed by Academy of Finland have supported the 3VPM methodology development, which is greatly appreciated.

\section{References}

1. Maliranta, M., Rouvinen, P.: Informational mobility and productivity - Finnish evidence. Econ. Innov. New Techn. 15(6), 605-616 (2006)

2. Martikainen, O.: Productivity Improvements Enabled by ICT based Process Transformations. In: 3rd Balkan Conference in Informatics BCI 2007, Sofia, September 27-29, pp. 1 8 (2007)

3. Remenyi, D.: The Elusive Nature of Delivering Benefits from IT Investment. EJISE 3(1) (2000), http://www.ejise.com

4. Gunasekaran, A., Ngai, E.W.T., Gaughey, R.E.: Information technology and systems justification: A review for research and applications. Eur. J. Oper. Res. 173, 957-983 (2006)

5. Barclay, C.: Towards an integrated measurement of IS project performance: The project performance scorecard. Inf. Syst. Front. 10, 331-345 (2008)

6. Rummler, G., Brache, A.: Improving Performance. Jossey-Bass, San Francisco (1995)

7. Smith, H., Fingar, P.: Business Process Management. Meghan-Kiffer Press, tampa (2002)

8. Melville, N., Kraemer, C., Gurbaxani, V.: Review: Information technology and organizational performance: An integrative model of IT business value. MIS Quart 28(2), 283-322 (2004)

9. Martikainen, O., Alasalmi, A.: Multichannel Contact Strategy helps Outpatient Healthcare Access. J. The Institute of Telecommunications Professionals 2, part 2, $43-47$ (2008)

10. Hofacker, I., Vetschera, R.: Algorithmical approaches to business process design. Computers \& Operations Res. 28, 1253-1275 (2001)

11. Kallrath, J.: Solving planning and design problems in the process industry using mixed integer and global optimization. Ann. Oper. Res. 140, 339-373 (2005)

12. Davenport, T.H.: Putting the Enterprise into the Enterprise System. Harvard Business Review (July 1998)

13. Davenport, T.H., Short, J.E.: The new industrial engineering: Information technology and Business Process Redesign. Sloan Management Review 31(4), 11-27 (1990) 
14. Davenport, T.H.: Process Innovation. Harvard Business School Press (1993)

15. Hammer, M., Champy, J.: Reengineering the Corporation. Harper Business (1993)

16. Harmon, P.: Business Process Change. Morgan Kaufman Publishers, San Francisco (2003)

17. Choenni, S., Bakker, R., Baets, W.: On the Evaluation of Workflow Systems in Business Processes. EJISE 6(2) (2003), http: / / www. ejise.com

18. van der Aalst, W.M.P.: The Application of Petri Nets to Workflow Management. J. Circuits, Systems and Computers 8(1), 21-66 (1998)

19. Maliranta, M., Rouvinen, P.: Productivity effects of ICT in Finnish business. ETLA DP 852 (2003)

20. Object Management Group: Business Process Modeling Notation Specification, Final Adopted Specification dtc/06-02-01, OMG (February 2006)

21. Gelenbe, E., Pujolle, G.: Introduction to Queueing Networks. Wiley, Chichester (2001)

22. Reijers, H.A.: Design and Control of Workflow Processes: Business Process Management for the Service Industry. Springer, Heidelberg (2003)

23. Denning, P.J., Buzen, J.P.: The Operational Analysis of Queueing Network Models. ACM Computing Surveys 10(3), 225-261 (1978)

24. Hammer, M.: Re-engineering Work: Don't automate, obliterate. Harvard Business Review 68(4), 104-113 (1990)

25. Eriksson, H.-E., Penker, M.: Business Modeling with UML: Business patterns at Work. Wiley, Chichester (2001) 